\title{
Ability of medical students to calculate drug doses in children after their paediatric attachment
}

\author{
Kazeem A. OSHIKOYA, Idowu O. SENBANJO, Ayo SOIPE.
}

Received (first version): 1-Sep-2008 Accepted: 7-Oct-2008

\begin{abstract}
Dose calculation errors constitute a significant part of prescribing errors which might have resulted from informal teaching of the topic in medical schools. Objectives: To determine adequacy of knowledge and skills of drug dose calculations in children acquired by medical students during their clinical attachment in paediatrics.

Methods: Fifty two 5th year medical students of the Lagos State University College of Medicine (LASUCOM), Ikeja were examined on drug dose calculations from a vial and ampoules of injections, syrup and suspension, and tablet formulation. The examination was with a structured questionnaire mostly in the form of multiple choice questions. Results: Thirty-six (69.2\%) and $30(57.7 \%)$ students were taught drug dose calculation in neonatal posting and during ward rounds/ bed-side teaching, respectively. Less than $50 \%$ of the students were able to calculate the correct doses of each of adrenaline, gentamicin, chloroquine and sodium bicarbonate injections required by the patient. Dose calculation was however relatively better with adrenalin when compared with the other injections. The proportion of female students that calculated the correct doses of quinine syrup and cefuroxime suspension were significantly higher than those of their male counterparts $(p<0.05$ and $p<0.01$, respectively; Chi-square test).

When doses calculated in $\mathrm{mg} /$ dose and $\mathrm{mL} /$ dose was compared for adrenalin injection and each of quinine syrup and cefuroxime suspension, there were significant differences (adrenaline and quinine, $p=0.005$; adrenaline and cefuroxime, $p=0.003$ : Fischer's exact test). Dose calculation errors of similar magnitude to injections, syrup and suspension were also observed with tablet formulation.

Conclusions: LASUCOM medical students lacked the basic knowledge of paediatric drug dose calculations but were willing to learn if the topic was formally taught. Drug dose calculations should be given a prominent consideration in the undergraduate medical curriculum in Nigeria.
\end{abstract}

Keywords: Drug Dosage Calculations. Clinical competence. Students, Medical Pediatrics. Nigeria.

\footnotetext{
Kazeem A. OSHIKOYA. Pharmacology Department, Lagos State University College of Medicine, and Paediatric Department, Lagos State University Teaching Hospital. Lagos (Nigeria).

Idowu O. SENBANJO. Paediatrics and Child Health, Lagos State University Teaching Hospital. Lagos (Nigeria) Ayo SOIPE. Medical Student, Lagos State University College of Medicine. Lagos (Nigeria).
}

\section{CAPACIDAD DE LOS ESTUDIANTES DE MEDICINA PARA CALCULAR DOSIS DE MEDICAMENTOS EN NIÑOS DESPUÉS DE SU INTERNADO EN PEDIATRÍA}

\section{RESUMEN}

Los errores de cálculos de dosis constituyen una parte significativa de los errores de prescripción que podría deberse a una enseñanza informal de este asunto en las facultades de medicina. Objetivos: Determinar la idoneidad de conocimientos y habilidades de cálculo de dosis de medicamentos para niños adquiridas por estudiantes de medicina durante su internado en pediatría.

Métodos: Se examinó a 52 estudiantes de medicina de la facultad de medicina de la Universidad Estatal de Lagos (LASUCOM) en Ikeja sobre cálculos de dosis de viales y ampollas de inyectables, jarabes y suspensiones, y tabletas. El examen fie un cuestionario estructurado mayoritariamente en la forma de preguntas de respuesta múltiple. Resultados: Se enseño el cálculo de dosis a 36 $(69,2 \%)$ y $30(57,7 \%)$ de los estudiantes en el servicio de neonatos y en las rondas/cabecera de cama, respectivamente. Menos del $50 \%$ de los estudiantes fueron capaces de calcular correctamente las dosis requeridas por cada paciente de cada inyección de adrenalina, gentamicina, cloroquina y bicarbonato sódico. Sin embargo, los cálculos de dosis fueron relativamente mejores para la adrenalina que con las otras inyecciones. La proporción femenina de de estudiantes que calculó correctamente la dosis de jarabe de quinina y suspensión de cefuroxima fue significativamente superior a la masculina $(p<0.05$ and $\mathrm{p}<0.01$, respectivamente; Chi-square test). Cuando se comaparban las dosis calculadas en $\mathrm{mg} /$ dosis y $\mathrm{mL} /$ dosis para inyección de adrenalina y para cada jarabe de quinina o suspensión de cefuroxima, había diferencias significativas (adrenalina and quinina, $\mathrm{p}=0.005$; adrenalina and cefuroxima, $p=0.003$ : prueba exacta de Fischer). Se observaron errores de cálculo de dosis para las tabletas de magnitud similar a los de los inyectables, jarabes y suspensiones. Conclusiones: Los estudiantes de medicina de LASUCOM carecían de conocimientos básicos de cálculos de dosis pediátricas, pero podían aprenderlos si este asunto se enseñaba formalmente. Debería darse una consideración prominente a los cálculos de dosis de 
medicamentos en el currículo pregraduado de medicina en Nigeria.

Palabras clave: Cálculos de dosis de medicamentos. Competencia clínica. Estudiantes de medicina. Pediatría. Nigeria.

\section{INTRODUCTION}

Medical students and interns in Nigeria have a poor understanding of different ways of expressing concentrations of drugs in solution and calculating doses of drugs from ampoules and vials of injections for paediatric use. These deficiencies were very glaring amongst interns who did their internship at the Lagos State University Teaching Hospital (LASUTH), Ikeja, over the past three years, especially during their paediatric attachment. The interns were graduates of different medical schools from Nigeria and abroad. No study has been done to support this claim. However, the interns admitted to being deficient in paediatric drug dose calculations. The deficiencies were attributed to lack of formal teaching of the topic in their various medical schools. For this reason, efforts were usually made by the resident doctors and consultants to teach the interns and medical students drug dose calculations during ward rounds and bedside teaching during paediatric attachment. Similarly, the prescriptions written by interns were regularly supervised and reviewed by both the residents and consultants to minimise prescribing errors.

Prescribing errors are the most common cause of preventable adverse drug events. ${ }^{1}$ Errors in the use of dosage equations account for more than $15 \%$ of all medication prescribing errors in America, with significant potential for producing adverse effects. ${ }^{2}$ Poor understanding of different ways of expressing the concentration of drugs in solution, dose calculation errors, and drug administration errors appears to be a global problem for medical students and doctors. ${ }^{3-9}$ At the Lagos State University College of Medicine (LASUCOM) and many other medical schools in Nigeria, dose calculations of drugs in children were rarely taught in a formal lecture to the medical students in both pharmacology and paediatric. As a way of minimising drug dose errors, it was recommended that ampoule and vial labels be standardised to mass concentration ${ }^{10}$, and drug administration, as well as dose calculations, be taught in either clinical anaesthesia or pharmacology. ${ }^{10-12}$ The good effect of an online teaching module designed to improve medical students' drug dose calculations and administration skills at the University of Cambridge, UK has been reported. ${ }^{13}$

The fifth year medical students who had completed their paediatric attachment and due for 3rd MBBS professional degrees examinations were assessed for their knowledge of drug dose calculations in children. Many of the previous studies have concentrated on drugs in solution ${ }^{3-7}$; however, none has assessed the ability of medical students and doctors to accurately calculate drug doses in syrup, suspension and tablet formulations.

This study was therefore aimed to determine adequacy of knowledge acquired by medical students to calculate paediatric drug doses in injections, syrup, suspension, and tablet formulations after their paediatric attachment.

\section{METHODS}

\section{Setting}

Medical students in their 5th year at the Lagos State University College of Medicine (LASUCOM), Ikeja were involved in the study. These are the third set of medical students admitted since the inception of the College in 1998. The class consisted of 75 students of whom 52 consented to partake in the study. The students had completed their paediatric attachment and were about to write 3rd MB; BS degrees professional examinations in the month of October, 2007. During their attachment in paediatrics, they had didactic lectures in general and systemic paediatric health problems, as well as infectious diseases for 6 months. However the lectures did not include drug dose calculations. In addition to the lectures, the medical students took part in clinical aspects of paediatrics such as attending the outpatient clinics, children emergency room (CHER), ward rounds and bedside teachings, clinical meetings and hospital ground rounds. During the rounds in the CHER, neonatal wards, and on the children's wards, medical students were sometimes taught drug dose calculations.

\section{Questionnaire Design}

A structured questionnaire; in the form of multiple choice questions, designed by two of the researchers (KAO and IOS), was the survey instrument. The questionnaire was divided into six parts; five of which were in multiple choice question (MCQ) forms. While the first part sought information about the demography of the students, the other parts investigated their knowledge on drug dose calculation from ampoules of injections, a vial of injection, syrup, suspension and tablet. Drugs that were readily available in the hospital, used very often on the wards and CHER were used for illustrations; believing that the students would be very familiar with them. Drugs used for the illustrations were a vial of ceftriaxone injection $(1 \mathrm{~g} / 2 \mathrm{~mL}$ powder); ampoules of adrenaline $(1 \mathrm{mg} / 1 \mathrm{~mL})$, gentamicin $(80 \mathrm{mg} / 2 \mathrm{~mL})$, chloroquine phosphate $(200 \mathrm{mg}$ base/ $5 \mathrm{~mL})$, and sodium bicarbonate $(8.4 \% \mathrm{w} / \mathrm{v}$ of $10 \mathrm{ml})$; quinine syrup $(100 \mathrm{mg} / 5 \mathrm{~mL})$; cefuroxime suspension $(20 \mathrm{mg} / 5 \mathrm{~mL})$ and artesunate tablet (50mg/tablet). Clinical scenarios, where these drugs were recommended for use, were given to the students and various different doses of the drugs were to be determined.

About the injections, knowledge of the medical students on how to constitute a vial of injection into solutions and how to measure out low doses of the injection in milligram and millilitres from the solution 
were investigated. Re-dilution of low dose of drugs in milligram and millilitre from ampoules of injections was also investigated. Knowledge of constitution of powder/granules to suspension and dose calculations in both milligram and millilitre from the suspension and syrup were equally assessed. Some tablets, especially the slow releasing ones, are available as breakable drugs. Knowledge of doses of such tablet in milligram and unit numbers was also investigated.

\section{Questionnaire Administration}

The questionnaire was administered to the students immediately after writing the end of paediatrics attachment assessment examination; to be filled and returned on the spot. They were allowed a maximum of one hour to answer the questions. All the students were given access to the national drug formulary and electronic machines to assist them in the calculations

\section{Ethical Considerations}

Permission to conduct the study was obtained from our institutional ethics committee. The students were informed to maintain anonymity in the filling of the questionnaire and were assured that their responses would not count against them in their performances in the assessment examination.

\section{Data Analysis}

Each correct answer was counted as one and a wrong answer as zero. The total number of correct answers to each question represents the recorded frequency. An acceptable $50 \%$ pass rate was used in this study because this was the minimum pass rate used in the end of posting assessment examination. Analysis of data was by SPSS 13.0 statistical package. Frequency distribution and proportion were determined for all the assessed parameters. Fisher's exact and chi-square tests were the non-parametric statistical tests used to compare performance relationships between students' gender and drug types at a significant level of $p<0.05$.

\section{RESULTS}

Fifty-two students (69.3\%) took part in the study, majority $(53.9 \%)$ were in the age group of $20-24$ years (age range 20-34 years), 30 (57.7\%) were female and 22 (42.3\%) male. Thirty-six (69.2\%) were taught drug dose calculations in neonatal posting, $30(57.7 \%)$ were taught during ward rounds and bed-side teaching, and $22(42.3 \%)$ were taught in paediatric emergency room.

During the paediatric attachment, drug dose calculations were taught to the students by 17 $(47.2 \%)$ junior residents, $14 \quad(38.9 \%)$ senior residents and 3 (8.3\%) consultants. Only15 (41.7\%) students claimed they understood drug dose calculations, of whom $12(80 \%)$ were satisfied with the teaching. Many of the students (42.3\%) believed that drug dose calculations should be taught in pharmacology, paediatrics, medicine, surgery, obstetrics and gynaecology, and anaesthesia; 9 $(17.3 \%)$ students believed they should be taught in pharmacology, paediatrics and anaesthesia; and 6 $(11.5 \%)$ be taught only in pharmacology. Pharmacology $(48.1 \%)$, anaesthesia $(28.9 \%)$ and paediatrics $(13.5 \%)$ were ranked the first subjects where drug dose calculations should be taught.

\section{Drug dose calculation from a vial of injection}

For appropriate dilution of one gramme, $2 \mathrm{~mL}$ powder of ceftriaxone injection, only $14(26.9 \%)$ and $3(5.8 \%)$ students, respectively, identified $6 \mathrm{~mL}$ and $3 \mathrm{~mL}$ sterile water for its constitution into solution so as to enable them measure accurately the required small dose. Based on the hypothetical clinical scenario used for illustration, only14 (26.9\%) students were able to correctly calculate the amount of injection in milligram per day and in divided doses, respectively, required by the patient. The volume equivalent of the injection in millilitre was correctly calculated by only $9(17.3 \%)$ students. The students' performances in drug dilution and dose calculation in milligram were significantly better than the expected $50 \%$ pass rate $(p<0.05$, Chi-square test). However, there were no significant differences in the proportion of male and female students that diluted the injection correctly $(p=0.52$, Chi-square test) and calculated the required dose in milligram ( $p=0.08$, Chi-square test)

\section{Dose calculation from an ampoule of injection}

Four different injections were used for illustrations, viz: adrenaline (1 mg/1 mL ampoule), gentamicin (80 mg/ $2 \mathrm{~mL}$ ampoule), chloroquine phosphate (200 $\mathrm{mg}$ base/ $5 \mathrm{~mL}$ ampoule), and sodium bicarbonate $(8.4 \% \mathrm{w} / \mathrm{v}$ of $10 \mathrm{~mL}$ ampoule). Figure 1 shows that less than $50 \%$ of the 52 students were able to calculate the correct doses of adrenaline, gentamicin, chloroquine, and sodium bicarbonate injections required by the patient. However, dose calculation was relatively better with adrenalin when compared with the other injections. For both adrenaline and gentamicin injections that required re-dilution to achieve the desired concentration, only $9 / 52(17.3 \%)$ students were able to determine the appropriate volume of sterile water required to redilute each of the injections. The volume in millilitre; equivalent to the required total dose in milligram for each of the injections, was correctly calculated by less than one-tenth of the students. There were no significant differences in the proportion of male and female students that calculated correctly the required doses in milligram for adrenaline $(p=0.32$, Chi-square test) and gentamicin ( $p=0.61$, Chisquare test).

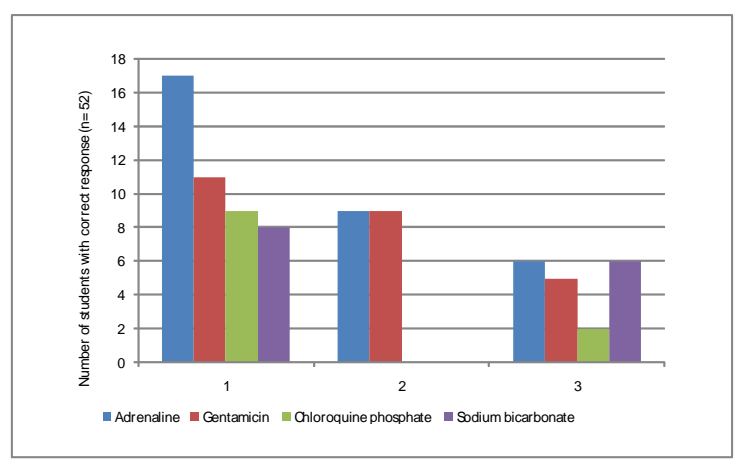

Figure 1: Dose calculation from ampoules of different injections. 
Comparing the dose calculations in milligram and millilitre for adrenaline and each of the other injections, there was no significant difference in the proportion of students that calculated the doses correctly for adrenaline and gentamicin $(p=0.53$, Fischer's exact test), adrenaline and chloroquine $(p=0.67$, Fischer's exact test), and adrenaline and sodium bicarbonate ( $p=0.33$, Fischer's exact test). The students' performance in dose calculation in milligram with adrenaline was not significantly different from the expected $50 \%$ pass rate $(p=0.07$, Chi-square test) but significantly woeful with gentamicin ( $p<0.01$, Chi-square test), chloroquine $(p<0.001$, Chi-square test), and sodium bicarbonate $(p<0.001$, Chi-square test). Dose calculations in millilitre was however a major problem of the students. Their performances were significantly poor for each of the injections when compared with the $50 \%$ pass rate $(p<0.001$, Chi-square test).

\section{Dose calculation from syrup/suspension}

Quinine syrup and cefuroxime suspension were the drugs used for illustrations. Table 1 shows that many of the students could not accurately calculate the drug dose parameters for quinine syrup. Only $8 / 52$ (15.4\%) students were able to correctly determine the dose of quinine in $\mathrm{mg} /$ dose and 18/52 $(34.6 \%)$ correctly determined the dose in $\mathrm{mL} /$ dose. Similar pattern of deficiencies in dose calculations was shown with cefuroxime suspension which is shown in Table 2. Only 6/52 (11.5\%) students were able to correctly determine the dose of cefuroxime in $\mathrm{mg} /$ dose and $17 / 52(32.7 \%)$ correctly determined its equivalent in $\mathrm{mL} /$ dose. The proportion of female students that calculated the correct doses of quinine syrup and cefuroxime suspension in $\mathrm{mg} /$ dose and $\mathrm{mL} /$ dose were significantly higher than those of their male counterparts $(p<0.05$ and $p<0.01$, respectively; Chi-square test).

\begin{tabular}{|l|c|c|}
\hline Table 1: Dose calculation from quinine syrup. Number of students with correct response $(\mathrm{n}=52)$ \\
\hline & $\mathrm{N}$ & $\%$ \\
\hline Amount of dose in $\mathrm{mL} /$ dose & 18 & 34.6 \\
\hline Total dose in $\mathrm{mL} / \mathrm{day}$ & 18 & 34.6 \\
\hline Total dose in $\mathrm{mL} / \mathrm{treatment}$ course & 13 & 25.0 \\
\hline Total dose in $\mathrm{mg} / \mathrm{treatment}$ course & 12 & 23.1 \\
\hline Amount of drug in mg/dose & 8 & 15.4 \\
\hline Total dose in $\mathrm{mg} / \mathrm{day}$ & 8 & 15.4 \\
\hline Total dose in $\mathrm{mg} / \mathrm{kg}$ & 7 & 13.5 \\
\hline Total dose in $\mathrm{mL} / \mathrm{kg}$ & 7 & 13.5 \\
\hline
\end{tabular}

\begin{tabular}{|c|c|c|}
\hline & $\mathrm{N}$ & $\%$ \\
\hline Volume of sterile water required for constitution & 19 & 36.5 \\
\hline Amount of drug in $\mathrm{mL} /$ dose & 17 & 32.7 \\
\hline Total dose in $\mathrm{mL} /$ day & 13 & 25.0 \\
\hline Total dose in $\mathrm{mL} /$ treatment course & 13 & 25.0 \\
\hline Amount in mg/bottle & 12 & 23.1 \\
\hline Total dose in mg/treatment course & 10 & 19.2 \\
\hline Number of required bottles /treatment course & 9 & 17.3 \\
\hline Total dose in mg/day & 8 & 15.4 \\
\hline Total dose in $\mathrm{mL} / \mathrm{kg}$ & 7 & 13.5 \\
\hline Total dose in $\mathrm{mg} / \mathrm{kg}$ & 6 & 11.5 \\
\hline Amount of dose in $\mathrm{mg} /$ dose & 6 & 11.5 \\
\hline
\end{tabular}

When doses calculated in $\mathrm{mg} /$ dose and $\mathrm{mL} /$ dose for adrenalin injection were compare with those of quinine syrup and cefuroxime suspension, there were significant differences (adrenaline and quinine, $p=0.005$; adrenaline and cefuroxime $p=0.003$ : Fischer's exact test. Contrarily, there was no significant difference in $\mathrm{mg} / \mathrm{dose}$ and $\mathrm{mL} / \mathrm{dose}$ concentrations calculated for quinine syrup and cefuroxime suspension ( $p=0.47$, Fischer's exact test). Comparing the performances of the students with the $50 \%$ expected pass rate, the students performed significantly well in calculated dose in $\mathrm{mL} /$ dose for quinine syrup ( $\mathrm{p}=0.09$, Chi-square test) but significantly woeful in calculated dose in $\mathrm{mg} /$ dose $(\mathrm{p}<0.001$, Chi-square test). Similarly, performance of the students was significantly good with dose calculation in $\mathrm{mL} /$ dose for cefuroxime $(p=0.07$, Chi-square test) but significantly poor for calculation in $\mathrm{mg} /$ dose $(\mathrm{p}<0.001$, Chi-square test).

\section{Dose calculation from tablets}

Artesunate was the tablet used for illustration; eight (15.4\%) students were able to determine the total drug in milligram required for a full course treatment of malaria. The equivalent number of tablets needed by the patient for a full course treatment was correctly determined by seven (13.5\%) students. Only five $(9.6 \%)$ students were able to accurately determine the number of tablets per dose required by the patient.

\section{DISCUSSION}

A response rate of $69.3 \%$ was obtained in this study. Even though this was a high rate, the proportion of non-participating students was rather significant. A plausible explanation for this is that, most likely, many of these students were among those that did not do well in the end of attachment assessment examination. Having made a self assessment of their poor performance in the 
examination, they got easily disinterested in the study. Therefore, a short coming of this study was a wrong timing for the questionnaire administration.

We found that medical students were deficient in all aspects of drug dose calculations. However, they were better off in dose calculation with adrenaline, compared to other injections illustrated in ampoules. This finding is a contrast to reports of previous studies $3,4,6,7,14$ where dose calculation with adrenaline was a major problem. This improvement may be attributed to the mass concentrated adrenaline used for our illustration instead of the ratio labelled types used in the previous studies. This finding further support previous studies that recommended standardized mass concentration $(\mathrm{mg} / \mathrm{mL})$ of adrenaline. ${ }^{4,7,14}$

We also observed that the students performed fairly well in dose calculation with syrup and suspension. This must have resulted from their familiarisation with syrup and suspension administration by parents to their children on admission. Injections were, most of the time, administered by the nurses; thus medical students may not be opportune to get familiar with dose calculations with injections. Experience, familiarity and frequent practice with drug administration tend to reinforce drug dose calculations of nurses ${ }^{15}$; yet it was indicated by the students that nurses were not among those who taught them drug dose calculations during their paediatric attachment. The females were observed to significantly perform better than their male counterparts in dose calculations with syrup and suspension. This may be because female medical students tend to attend CHER and ward rounds or spend time with children on admission more than their male counterparts.

Adrenaline was purposively used for illustration in this study because it is a major drug for resuscitation in paediatrics. Drug dose errors had been reported to be especially high during resuscitation and with resuscitation drugs ${ }^{16}$; such error was similarly associated with adrenaline injection in this study. However, the clinical consequences of adrenaline overdose that might have followed the incorrect dose calculations made by the students may not be as grave in children as in adults. ${ }^{14}$

Dose calculation errors were not limited only to injections but may also involve syrup/suspension and tablets as observed in this study. Physicians and nurses involved in previous studies from America $^{2,17}$ and $\mathrm{UK}^{4,18,19}$, regarding dosage regimen calculation have been reported to perform very poorly on the standardized tests similar in magnitude to the ones observed in this study. It was therefore evident that drug dose calculation error would continue to remain a global problem unless adequately and formally taught in the medical schools.

The overall poor performance of the students in all aspect of drug dose calculations is of great concern. This may therefore necessitates inclusion of formal teaching of drug dose calculations in undergraduate medical curriculum in Nigeria. A good way to achieve this is to include teaching of the topic in pharmacology and/or paediatrics lectures. The students should also be made to practise many exercises on drug dose calculations in the undergraduate pharmacology practicals; similar to the method proposed by Parmar et al., ${ }^{12}$ in India for teaching dose calculations for intravenous infusion. It is also very likely that the topic would be embraced by the students, if introduced into the curriculum, as evident by the $42.3 \%$ students that wanted drug dose calculations formally taught in pharmacology, paediatrics, medicine, surgery, obstetrics and gynaecology, and anaesthesia.

The ranking of teaching of drug dose calculations first and foremost in pharmacology, followed by anaesthesia and paediatrics, showed that formal teaching of the topic could begin in pharmacology and further teaching is done in anaesthesia and paediatrics so as to reinforce the assimilation and knowledge of the students on this topic; a very good strategy of learning. ${ }^{20}$ The Nigerian Medical and Dental Council (NMDC); a body that regulates medical education in Nigeria, should emulate the General Medical Council of the UK on undergraduate medical education ${ }^{21}$ by recommending a good knowledge and skill of drug dose calculation as a pre-requisite for pre-internship registration.

Only drugs commonly used in paediatric treatments that likely had been seen by the students were used for the illustrations in this study. Drug dose calculations using body surface area (BSA) was excluded from the study because such calculations are limited to a few numbers of drugs such as anticancer drugs and the method of calculation is more cumbersome. ${ }^{22}$

A potential criticism of this study is that the students were not formally taught drug dose calculations; therefore the effect of teaching the topic could not be assessed. We however limited ourselves to this study since we only aimed at assessing the adequacy of the knowledge acquired by the students on drug dose calculations during their attachment in paediatrics. Further studies are therefore suggested to assess the impact of formal teaching of the topic to students. A questionnaire based study like this may not be able to provide insights into the problems and confusion encountered by the students while under pressure in real clinical settings. We therefore suggest further studies that would include clinical simulation to ascertain the confidence to carry out drug dose calculations with accuracy in a clinical setting by the tomorrow's doctors. Guessing is also a major set back of MCQ examinations. However, awarding no penalty for any wrong answer would likely give room for more guess, thus the responses obtained may not me a true reflection of the students' knowledge. Lastly, the study population was small and involved only one medical school. The generalizability of our findings is therefore unknown. Further study that would involve students from other medical schools in Nigeria is therefore suggested. 


\section{CONCLUSIONS}

Undergraduate medical students of the LASUCOM were deficient in paediatric drug dose calculation. However, they were willing to learn if the topic was introduced into their curriculum. Formal teaching of drug dose calculations and reinforcement during ward rounds and bedside teaching would appear to be needed. We therefore recommend that drug dose calculations are given a prominent place in the undergraduate medical curriculum in Nigeria whenever it is due for a review.

\section{CONFLICT OF INTEREST}

None declared.

\section{References}

1. Bates DW, Cullen DJ, Laird N, Petersen LA, Small SD, Servi D, Laffel G, Sweitzer BJ, Shea BF, Hallisey R, et al. Incidence of adverse drug events and potential adverse drug events: implications for prevention. JAMA. 1995;274(1):29-34.

2. Lesar TS, Briceland LL, Stein DS. Factors related to errors in medication prescribing. JAMA. 1997;277:312-317.

3. Wheeler DW, Remoundos DD, Whittlestone KD, House TP, Menon DK. Calculation of drugs in solution: are medical students confuse by different means of expressing drug concentrations? Drug Saf. 2004;27(10):729-734.

4. Rolfe S, Harper NJ. Ability of hospital doctors to calculate doses. Br Med J. 1995;310:1173-1174.

5. Scrimshire JA. Safe use of lignocaine. Br Med J. 1989;298:1494.

6. Wheeler DW, Remoundos DD, Whittlestone KD, Palmer MI, Wheeler SJ, Ringrose TR, Menon DK. Doctors' confusion over ratios and percentages in drug solutions: the case for standard labelling. J R Soc Med. 2004;97(8):380-383.

7. Oldridge GJ, Gray KM, McDermott LM, Kirkpatrick CM. Pilot study to determine the ability of health-care professionals to undertake drug dose calculations. Int Med J. 2004;34(6):316-319.

8. Oshikoya KA, Ojo OI. Medication errors in paediatric outpatient prescriptions in Nigeria. Niger Quart J Hosp Med. 2007;17:74-78.

9. Lack JA, Stuart-Taylor ME. Calculation of drug dosage and body surface area of children. Br J Anaesth 1997;78:601-605.

10. Wheeler SJ, Wheeler DW. Dose calculation and medication error-why are we still weakened by strength? Eur J Anaesthesiol. 2004;21:929-931.

11. Wheeler DW, Whittlestone KD, Salvador R, Wood DF, Johnston AJ, Smith HL, Menon DK. Influence of improved teaching on medical students' acquisition and retention of drug administration skills. Br J Anaesth. 2006;96(1):48-52.

12. Parmar CM, Jadav SP. Teaching undergraduate students appropriate dose calculations in relation to intravenous infusion. Indian J Pharmacol. 2006;38:435-437.

13. Degnan BA, Murray LJ, Dunling CP, Whittlestone KD, Standley TD, Gupta AK, Wheeler DW. The effect of additional teaching on medical students' drug administration skills in a simulated emergency scenario. Anaesthesia. 2006;61(12):1155-1160.

14. Wheeler DW, Carter JJ, Murray LJ, Degnan BA, Dunling CP, Salvador R, Menon DK, Gupta AK. The effect of drug concentration expression on epinephrine dosing errors: a randomized trial. Ann Intern Med. 2008;148(1):11-14.

15. Adams A, Duffield C. The value of drills in developing and maintaining numeracy skills in an undergraduate nursing programme. Nurs Educ Today. 1991;11:213-219.

16. Kozer E, Scolnik D, Jarvis A, Koren G. The effect of detection approaches on the reported incidence of tenfold error. Drug Saf. 2006;29(2):169-174.

17. Timothy SL. Errors in the use of medication dosage equations. Arch Pediatr Adolesc Med. 1998;152:340-344.

18. Potts MJ, Phelan KW. Deficiencies in calculation and applied math skills in paediatrics among primary care interns. Arch Paediatr Adolesc Med. 1996; 150: 748-752.

19. Bayne T, Bindler R. Medication calculation skills of registered nurses. J Cont Educ Nurs. 1988;19:258-262.

20. Durrieu G, Hurault C, Bongard V, Damase-Michel C, Montastruc JL. Perception of risk of adverse drug reactions by medical students: influence of a 1 year pharmacological course. Br J Clin Pharmacol. 2007;64(2):233-236.

21. GMC. Tomorrow's Doctors. Recommendations on Undergraduate Medical Education. London: General Medical Council, 2003.

22. Tripathi KD. Essential of medical pharmacology. 5th ed. New Delhi, India: Jaypee Brothers Medical Publishers (P) Ltd; 2003. 